\title{
Clinical Impact of Checkpoint Inhibitors as Novel Cancer Therapies
}

\author{
Kent Shih $\cdot$ Hendrik-Tobias Arkenau • \\ Jeffrey R. Infante
}

Published online: 25 October 2014

(c) The Author(s) 2014. This article is published with open access at Springerlink.com

\begin{abstract}
Immune responses are tightly regulated via signaling through numerous co-stimulatory and co-inhibitory molecules. Exploitation of these immune checkpoint pathways is one of the mechanisms by which tumors evade and/or escape the immune system. A growing understanding of the biology of immune checkpoints and tumor immunology has led to the development of monoclonal antibodies designed to target co-stimulatory and co-inhibitory molecules in order to re-engage the immune system and restore antitumor immune responses. Anti-cytotoxic T-lymphocyte-associated antigen 4 (CTLA-4) antibodies were among the first to be tested in the clinic, and ipilimumab was the first immune checkpoint inhibitor approved for an anticancer indication. Agents targeting the programmed death 1 (PD-1) pathway, either PD-1 or one of its ligands, programmed death ligand 1 , are in active clinical development for numerous cancers, including advanced melanoma and lung cancer. Understanding the different mechanisms of action, safety profiles, and response patterns associated with inhibition of the CTLA-4 and PD-1 pathways may improve patient management as these therapies are moved in to the clinical practice setting and may also provide a rationale for combination therapy with different inhibitors. Additional immune checkpoint molecules with therapeutic potential, including lymphocyte activation gene-3 and glucocorticoid-induced tumor necrosis factor receptor-related gene, also have inhibitors in early stages of clinical development. Clinical responses and safety data reported to date on immune checkpoint
\end{abstract}

This article is part of the topical collection on Immuno-Oncology.

K. Shih $(\varangle) \cdot$ H.-T. Arkenau · J. R. Infante

Sarah Cannon Research Institute and Tennessee Oncology PLLC, Nashville, TN 37203, USA

e-mail: kshih@tnonc.com inhibitors suggest these agents may have the potential to markedly improve outcomes for patients with cancer.

\section{Key Points}

Immune checkpoint inhibitors are designed to interrupt inhibitory immune signals and restore immune responses against tumors.

Numerous immune checkpoint inhibitors are in advanced stages of development and show activity across multiple tumor types, including advanced melanoma and advanced non-small-cell lung cancer.

Understanding the mechanism-associated adverse events and response patterns is important to the management of patients as these drugs are moved into the clinical practice setting.

\section{Introduction}

Rudolph Virchow may have been one of the first physicians in modern times to observe the link between the immune system and malignancy in what he termed "lymphoreticular infiltrates". These infiltrates were leukocytes surrounding malignant tumors, and he hypothesized that proinflammatory states might induce normal tissues to become malignant [1]. Since then, we have learned a great deal about how the immune system responds and reacts to tumors, which tumor-specific antigens are recognized as foreign, and how immune responses can be manipulated and harnessed to enhance tumor cell killing. 
Recently, it has been recognized that, on its own, tumor peptide presentation by major histocompatibility complex (MHC) to T-cell receptors is inadequate for successful T-cell activation and immune destruction of cancer cells. Co-regulatory signals, either inhibitory or stimulatory, are also required $[2,3]$. T cells play a critical role in cellmediated tumor immunity, and do so through an intricate counterbalance of co-stimulatory and co-inhibitory cell-tocell signals between various components of the immune system. This system of checks and balances is necessary not only to allow a powerful destructive response against both pathogens and malignancies, but also to prevent immune responses from being generated against normal tissues. Critical 'checkpoints' control and fine-tune the immune system through regulation of this complex network of co-stimulatory and co-inhibitory signaling [3]. In this paper, we review some of the important immune checkpoint molecules elucidated to date, as well as efforts to block these molecules in order to shift the balance towards antitumor immunity. We also describe some of the complexities and challenges encountered using these checkpoint inhibitors in the clinic.

\section{Cytotoxic T-Lymphocyte-Associated Antigen (CTLA)-4}

\subsection{Background}

More than 40 years of research has led to the development of a two-signal theory of T-cell activation: antigenic stimulation of the T-cell receptor (TCR) (signal 1) together with co-stimulation by other molecules on the cell surface (signal 2) [2,3]. One of the key co-stimulatory mechanisms involves the interaction of CD28 on the surface of the T cell with B7 molecules CD80 or CD86 on antigen-presenting cells. CTLA-4, a transmembrane glycoprotein with considerable homology to $\mathrm{CD} 28$, binds to the same B7 ligands, as such (Fig. 1). Upon TCR stimulation by antigens, $T$ cells express CTLA-4, which can bind B7 molecules; however, unlike CD28, CTLA-4 inhibits T-cell responses and is important for maintenance of immune tolerance. Expression of CTLA-4 raises the activation threshold and attenuates clonal expansion; thus, a productive T-cell response ensues only upon a net co-stimulatory signal.

\subsection{Efficacy of CTLA-4 Inhibitors}

\subsubsection{Ipilimumab}

Ipilimumab, one of the best-studied monoclonal antibodies targeting CTLA-4 (Table 1 [4-16]), has been evaluated in
Antigen presenting cell/Tumor

T cell

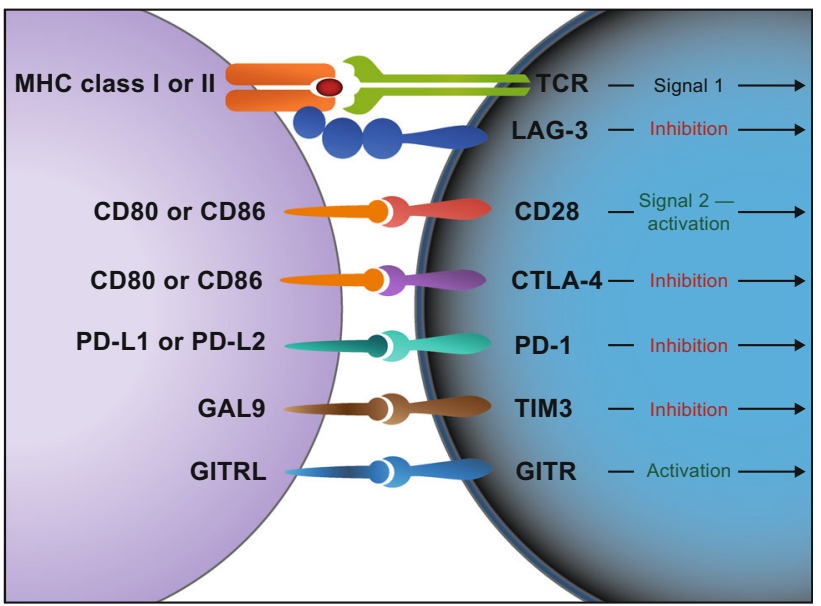

Fig. 1 T-cell activation and immune checkpoint pathways. T-cell activation requires two signals: (1) presentation of antigenic peptides by MHC to the TCR and (2) co-stimulation, typically via CD28:CD80 or CD28:CD86 ligation. Immune checkpoint pathways comprising receptors on $\mathrm{T}$ cells and ligands on antigen-presenting cells and/or tumors fine-tune immune responses via T-cell activation or inhibition. CTLA-4 cytotoxic T-lymphocyte-associated antigen 4, GAL9 galectin-9, GITR glucocorticoid-induced TNF receptor-related gene, GIT$R L$ glucocorticoid-induced TNF receptor-related gene ligand, $L A G-3$ lymphocyte activation gene-3, $M H C$ major histocompatibility complex, $P D-1$ programmed death-1, $P D-L 1$ programmed death ligand 1 , $P D$ - $L 2$ programmed death ligand 2, TCR T-cell receptor, TIM3 T-cell immunoglobulin and mucin domain 3,TNF tumor necrosis factor

a clinical trial program of more than 2,000 patients with a variety of solid tumors [4, 5, 17-19]. Ipilimumab (Yervoy $\left.{ }^{\circledR}\right)$, administered every 3 weeks for four doses, gained US FDA approval in 2011 for the treatment of unresectable or metastatic melanoma, based on data from two phase III randomized trials showing improvement on median overall survival (OS) over control arms in patients with melanoma $[4,5,20]$. One of the pivotal phase III trials evaluated ipilimumab with or without gp100 vaccine in previously treated patients with advanced melanoma. Although the best overall response rates were modest, $10.9 \%$ in the ipilimumab-alone group and $5.7 \%$ in the ipilimumab plus gp100 vaccine group, some patients in both groups maintained an objective response for at least 2 years [4]. In this trial, the 3-year OS rate for ipilimumab monotherapy was $20 \%$ [4], which compares favorably with the 3-year OS rate of $17 \%$ for historical control patients receiving standard of care chemotherapy in a separate clinical trial [21] (Table $2[4,5,7,18,19,21-33])$. The other pivotal phase III trial was conducted in treatment-naïve patients with metastatic melanoma and compared ipilimumab plus dacarbazine versus dacarbazine plus placebo [5]. Although the dose and schedule were slightly different, the rate of best overall response was $15 \%$ in the ipilimumab plus dacarbazine group versus $10 \%$ for the dacarbazine plus 
Table 1 Immune checkpoint inhibitors in clinical development [4-16]

\begin{tabular}{lll}
\hline Name & Company & Description of agent \\
\hline Ipilimumab [4, 5] & Bristol-Myers Squibb & Human IgG1 mAb against CTLA-4 \\
Tremelimumab [6] & MedImmune/AstraZeneca & Human IgG2 mAb against CTLA-4 \\
Pembrolizumab (MK-3475) [7] & Merck & Humanized IgG4 mAb against PD-1 \\
Nivolumab (BMS-936558) [8] & Bristol-Myers Squibb & Human IgG4 mAb against PD-1 \\
Pidilizumab (CT-011) [9] & CureTech & Humanized IgG1 mAb against PD-1 \\
AMP-224 [10] & Amplimmune; GlaxoSmithKline & PD-L2-IgG recombinant fusion protein \\
MPDL3280A [11, 12] & Genentech/Roche & Human IgG mAb against PD-L1 \\
BMS-936559 [13] & Bristol-Myers Squibb & Human IgG4 mAb against PD-L1 \\
MEDI4736 [14] & MedImmune/AstraZeneca & Human mAb against PD-L1 \\
IMP321 [15] & Immutep & Soluble LAG-3 Ig fusion protein and MHC class II agonist \\
TRX518 [16] & GITR, Inc & Humanized mAb against GITR \\
\hline
\end{tabular}

CTLA-4 cytotoxic T-lymphocyte-associated antigen 4, GITR glucocorticoid-induced tumor necrosis factor receptor-related gene, $I g G$ immunoglobulin G, $L A G-3$ lymphocyte activation gene-3, $m A b$ monoclonal antibody, $M H C$ major histocompatibility complex, $P D-1$ programmed death 1, $P D$-L1 programmed death ligand 1, PD-L2 programmed death ligand 2

Table 2 Preliminary efficacy data with immune checkpoint inhibitors or controls from individual (not head-to-head) trials ${ }^{\mathrm{a}}[4,5,7,17,18$, 21-33]

\begin{tabular}{|c|c|c|c|c|c|}
\hline Advanced tumor setting & Agent or control & Median PFS & Median OS & Survival rate & Reference(s) \\
\hline \multirow[t]{7}{*}{ Melanoma } & CTX (CTX-naïve pts) & ND & 9.1-10.7 months & $\begin{array}{l}\text { 1-year: } 36 \% \\
\text { 3-year: } 12-17 \%\end{array}$ & {$[5,21]$} \\
\hline & Ipilimumab & 2.9 months & 10.1 months & 3 -year: $\approx 20 \%$ & [4] \\
\hline & Tremelimumab & ND & 12.6 months & 3-year: $21 \%$ & {$[21]$} \\
\hline & Pembrolizumab & 5.5 months & NR & 1-year: $69 \%$ & [7] \\
\hline & Nivolumab & 3.7 months & 17.3 months & $\begin{array}{l}\text { 1-year: } 63 \% \\
\text { 3-year: } 41 \%\end{array}$ & {$[22]$} \\
\hline & Pidilizumab & 1.9 months & ND & 1-year: $65 \%$ & [23] \\
\hline & Nivolumab plus ipilimumab & 27 weeks & 40 months & $\begin{array}{l}\text { 1-year: } 85 \% \\
\text { 2-year: } 79 \%\end{array}$ & {$[24]$} \\
\hline \multirow[t]{4}{*}{ NSCLC } & CTX (CTX-naïve pts) & 4.2 months & 8.3 months & $\begin{array}{l}\text { 1-year: } 39 \% \\
\text { 2-year: } 18 \%\end{array}$ & [18] \\
\hline & Pembrolizumab & $10-27$ weeks $^{\mathrm{b}}$ & 51 weeks & $\mathrm{ND}$ & [25-27] \\
\hline & Nivolumab (previously-treated pts) & 2.3 months & 9.9 months & $\begin{array}{l}\text { 1-year: } 42 \% \\
\text { 3-year: } 24 \%\end{array}$ & [28] \\
\hline & Nivolumab (CTX-naïve pts) & 36.1 weeks & NR & 1-year: $75 \%$ & [29] \\
\hline \multirow[t]{2}{*}{$\mathrm{RCC}$} & Sorafenib & 3.6-5.7 months & $11.0-19.2$ months & 3 -year: $\approx 25 \%$ & [30-32] \\
\hline & Nivolumab & $2.7-4.2^{\mathrm{c}}$ months & $18.2-24.7^{\mathrm{c}}$ months & 2.5 -year: $\approx 35 \%$ & {$[33]$} \\
\hline \multirow[t]{2}{*}{ CRPC } & Placebo & 3.1 months & 10.0 months & $\begin{array}{l}\text { 1-year: } 40 \% \\
\text { 2-year: } 15 \%\end{array}$ & [17] \\
\hline & Ipilimumab & 4.0 months & 11.2 months & $\begin{array}{l}\text { 1-year: } 47 \% \\
\text { 2-year: } 26 \%\end{array}$ & [17] \\
\hline
\end{tabular}

$C R P C$ castration-resistant prostate cancer, $C T X$ chemotherapy, $N D$ no data, $N R$ not reached, $N S C L C$ non-small-cell lung cancer, $O S$ overall survival, $P F S$ progression-free survival, pts patients, $R C C$ renal cell carcinoma

a Important: data are not from head-to-head trials, and the trials differ by patient characteristics, patient numbers, and length of follow-up, therefore direct comparisons across trials and agents have limited validity; trials in tumor types with PFS and OS data were included

b Based on differing studies and data-cuts

c Dose-dependent 
placebo group, while the median duration of response was 19.3 versus 8.1 months for the dacarbazine plus placebo group. Responses lasting at least 2 years were observed in both treatment groups. The 3 -year survival rate with ipilimumab plus dacarbazine was significantly higher than dacarbazine plus placebo: 20.8 versus $12.2 \%(P<0.001)$.

Ipilimumab was evaluated as adjuvant therapy following complete resection of stage III melanoma in a phase III trial in patients at high risk of recurrence [34]. Patients receiving ipilimumab had a significantly increased median OS as compared with patients receiving placebo: 26.1 versus 17.1 months $(P=0.0013)$. The 3 -year rates of recurrence-free survival were $47 \%$ for ipilimumab and $35 \%$ for placebo.

Preclinical studies suggest that chemotherapy can induce the release of tumor-specific antigens, thereby initiating T-cell activation and sensitizing tumor cells to T-cell-mediated killing [35]. These observations provided the rationale for combining immunotherapy with cytotoxic agents to improve responses in patients with melanoma, and also led to the initiation of clinical trials evaluating ipilimumab with chemotherapy in lung cancer. A phase II, randomized study provided evidence that sequential ipilimumab is more effective than concurrent ipilimumab when administered with paclitaxel/carboplatin in chemotherapy-naïve stage IIIB/IV patients with non-small-cell lung cancer (NSCLC). The median OS with sequential ipilimumab, concurrent ipilimumab, and the control regimen was $12.2,9.7$, and 8.3 months, respectively. In this trial, patients with squamous histology exhibited better outcomes (median immune-related progression-free survival [irPFS] and OS) with sequential ipilimumab dosing than did patients with non-squamous histology [18]. Based on these findings, a phase III trial evaluating OS in patients with squamous NSCLC receiving sequential ipilimumab after chemotherapy was initiated (Table 3 [16]).

Ipilimumab is also being investigated in the setting of metastatic castration-resistant prostate cancer (mCRPC). In a phase III trial of ipilimumab versus placebo in post-docetaxel patients with $\mathrm{mCRPC}$ receiving a single dose of radiotherapy, the primary endpoint of OS was not reached; however, pre-specified subset analyses suggested that ipilimumab may be more active in patients with favorable prognostic factors, including no visceral disease, alkaline phosphatase $<1.5$ upper limit of normal, and hemoglobin $\geq 11 \mathrm{~g} / \mathrm{dL}$ [17]. Results from this study support the investigation of ipilimumab in the ongoing phase III, CA184-095 study among chemotherapy-naïve patients with mCRPC (Table 3 [16]).

\subsubsection{Tremelimumab}

Tremelimumab is a fully human immunoglobulin $\mathrm{G}$ (IgG)2 monoclonal antibody targeting CTLA-4 [6] (Table 1 [4-
16]). Tremelimumab provided durable responses in $6.6 \%$ of patients in a phase II trial of patients with advanced melanoma, as compared with the objective response rates (ORRs) of 5.7 and $10.9 \%$ seen in the phase III trial of ipilimumab with or without vaccine $[4,6]$. However, the phase III trial of tremelimumab monotherapy failed to demonstrate a statistically significant survival advantage over chemotherapy in first-line treatment of patients with metastatic melanoma [21]. Patient selection criteria, dosing regimen, and use of ipilimumab as salvage therapy for patients in the control arm were potential reasons for the lack of survival benefit.

Tremelimumab showed evidence of activity against previously treated malignant mesothelioma in a small $(N=29)$ phase II single-arm trial [36]. Four patients had partial responses, and 11 patients had stable disease of median duration 7.7 months (range 2.6-16.6+), with a median OS of 11.3 months. Based on these results, a phase II trial of tremelimumab in malignant mesothelioma has been initiated (Table 3 [16]).

\subsection{Safety of CTLA-4 Inhibitors}

The cumulative safety data across many trials show that agents that inhibit CTLA- 4 are generally safe, with unique, but usually manageable, side effects that are linked to their mechanism of stimulating immune responses. Multiple phase II and III trials have characterized these immunerelated adverse events (irAEs) of CTLA-4 inhibition. Overall, irAEs were observed in 58-63\% of patients treated with ipilimumab, with $5-26 \%$ of patients experiencing grade $3 / 4$ irAEs $[4,17,37]$ (Table $4[4,7,8,12-14$, $17,21,23,26,28,36,38-40])$. In the phase III trial investigating ipilimumab treatment with or without vaccine, skin-related irAEs (including pruritus, rash, and erythema) and gastrointestinal irAEs (including diarrhea and colitis) were the most common, occurring in $29-44 \%$ of patients; endocrine disorders were reported in $4-8 \%$ of patients [4]. Some of the more rare adverse events (AEs) ( $\leq 1 \%$ for each) reported during treatment with ipilimumab include uveitis, conjunctivitis, and neuropathy [37]. Interestingly, when ipilimumab was given with dacarbazine, immune-mediated grade $3 / 4$ hepatitis occurred in $32 \%$ of patients, while the rates of gastrointestinal events, such as colitis, were lower than expected based on previous trials [5]. As adjuvant therapy, ipilimumab had a safety profile generally consistent with that seen in patients with advanced melanoma, although the incidence of some irAEs (e.g. endocrinopathies) was higher. Also, five patients $(1 \%)$ in the ipilimumab arm died due to treatmentrelated AEs versus 0 patients in the placebo group [34]. Tremelimumab has a similar irAE profile to ipilimumab. The most common irAEs with tremelimumab were 


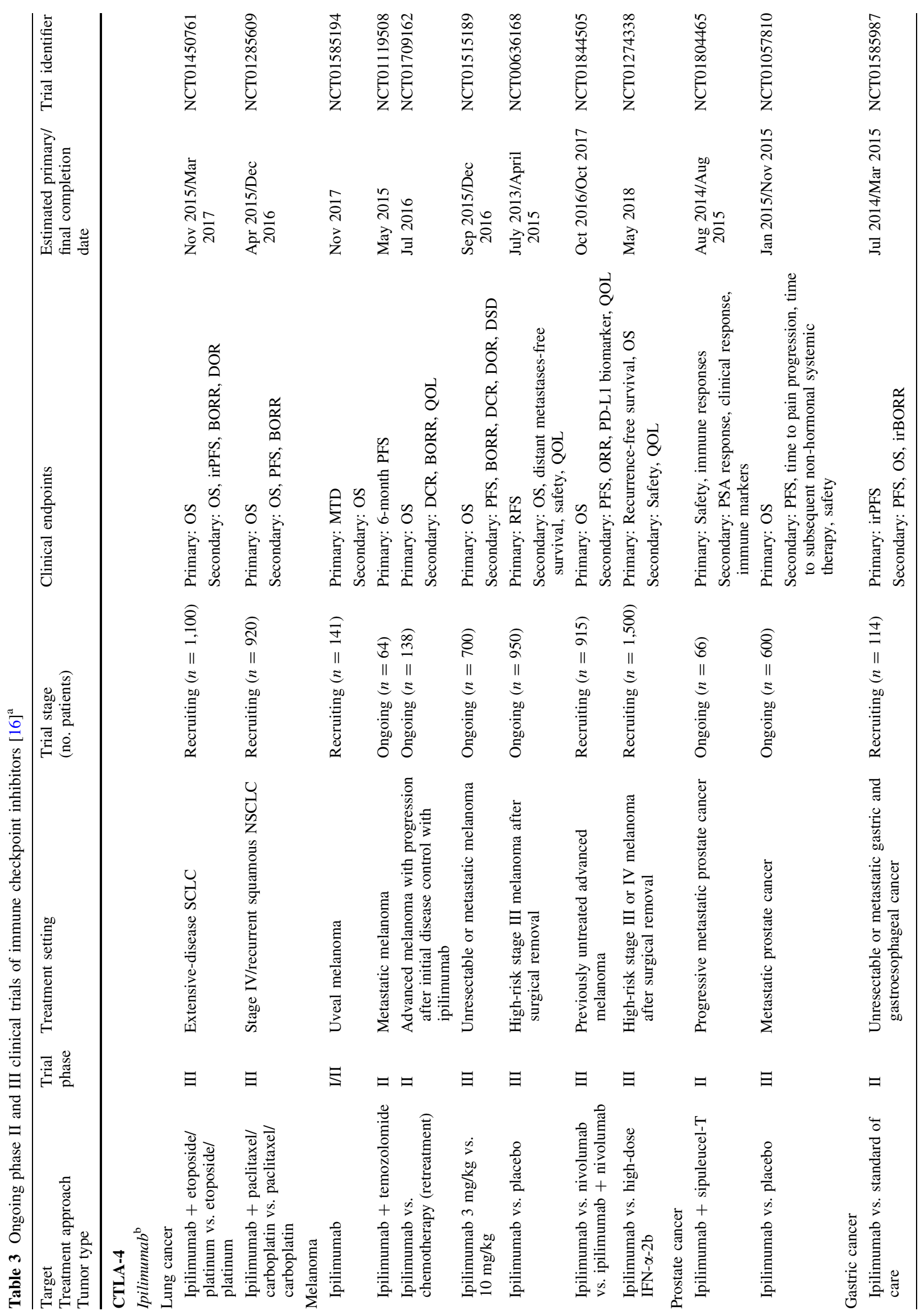




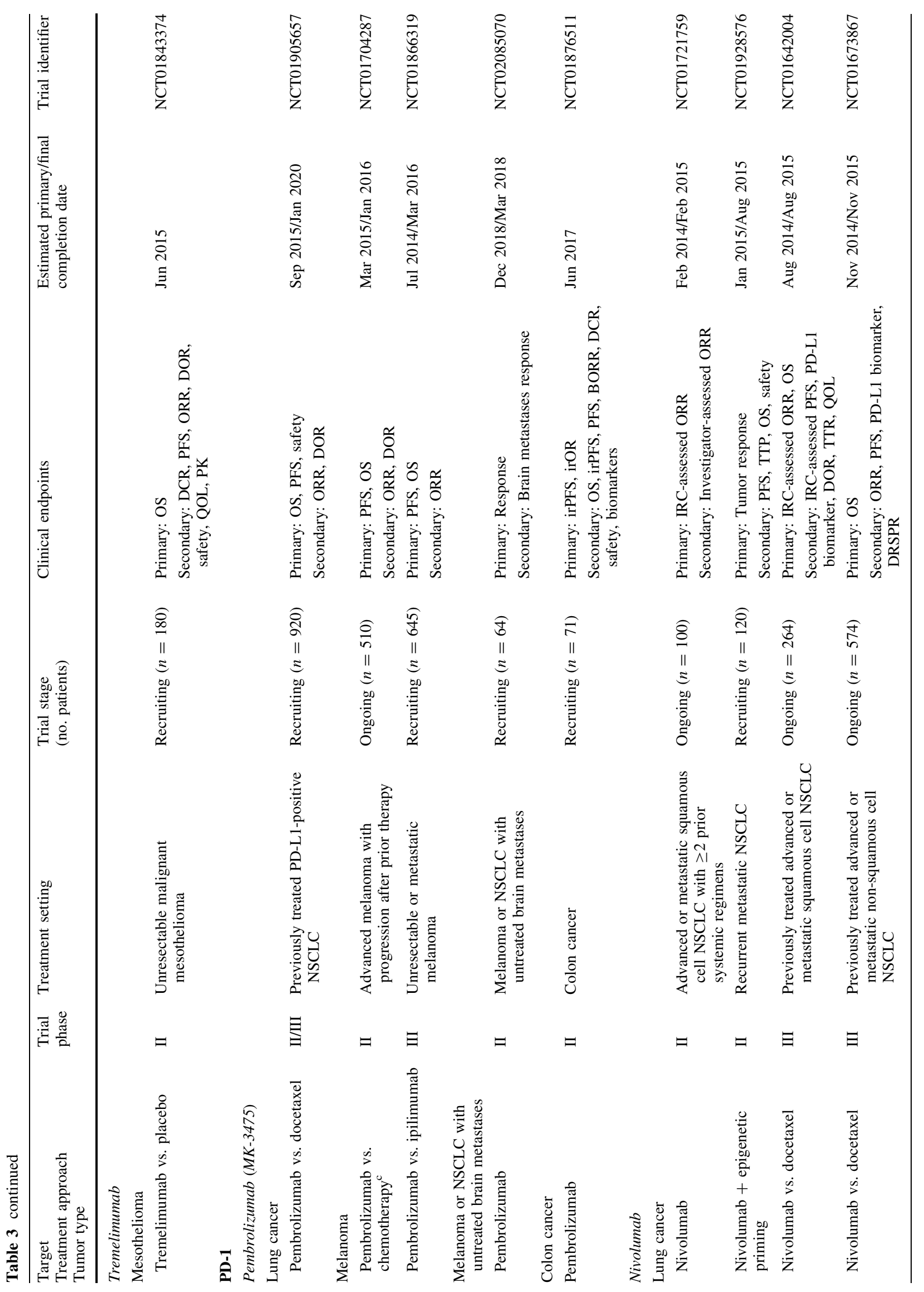




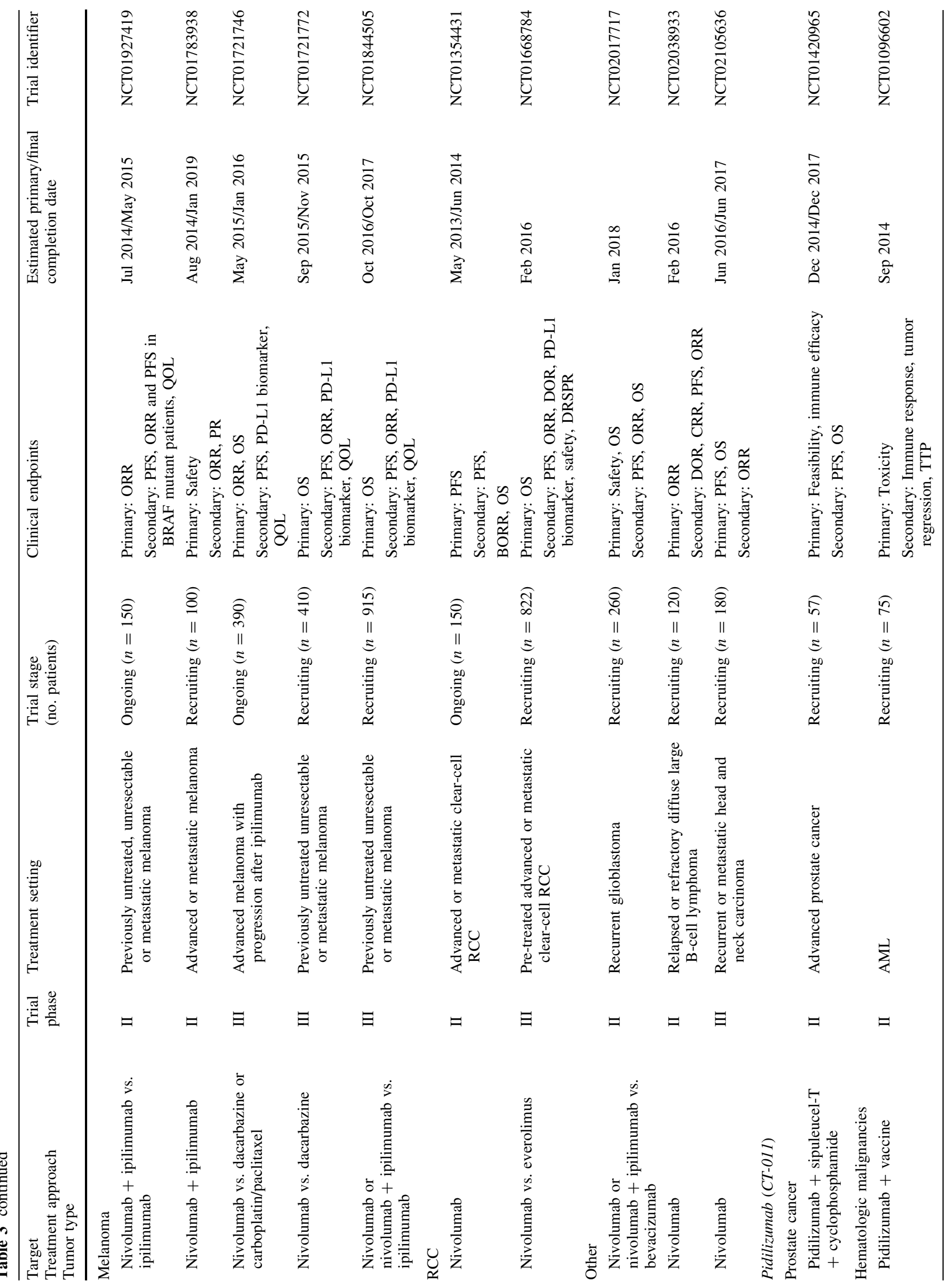




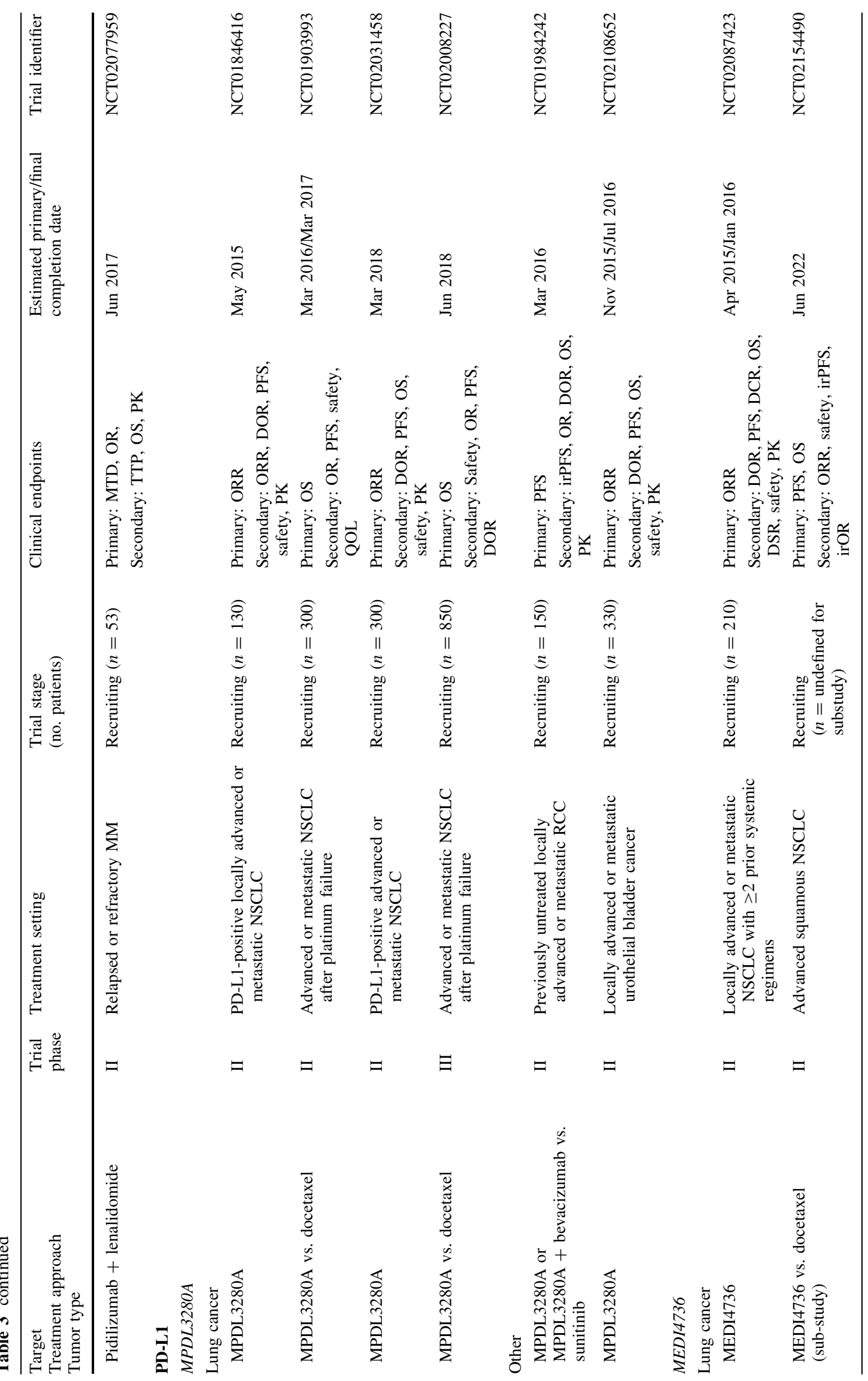




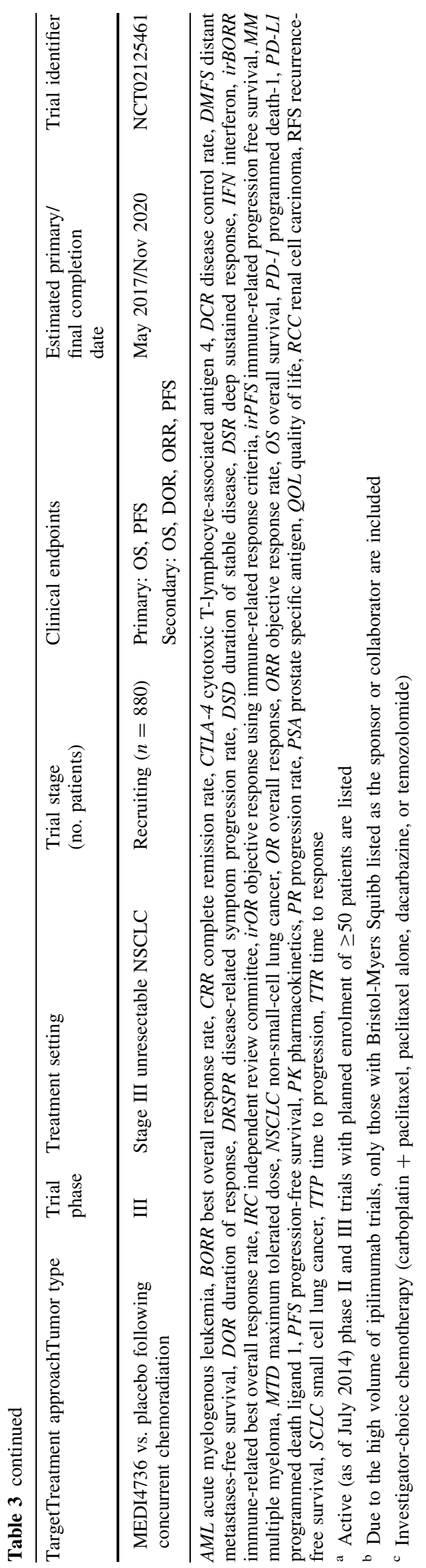

gastrointestinal (18\% grade 3-5), dermatologic (rash $33 \%$ all grades, $2 \%$ grade 3-5), and endocrine (thyroid/panhypopituitarism/adrenal insufficiency $7 \%$ ) in nature [21] (Table 4 [4, 7, 8, 12-14, 17, 21, 23, 26, 28, 36, 38-40]).

irAEs for CTLA-4 inhibitors tend to occur during the induction period or first 12 weeks of therapy, but, in rare cases, can occur in the weeks and even months following discontinuation of therapy [37]. Grade 2 irAEs are usually responsive to interruption of therapy and institution of lowdose steroids $(0.5 \mathrm{mg} / \mathrm{kg} /$ day of prednisone $)$, and grade 3 and higher irAEs are generally responsive to high-dose steroids (1-2 mg/kg/day of prednisone or equivalent), although the steroid-refractory patients (reported as 2-8\% of patients) [20, 41] may require the use of alternate immunosuppressive agents, such as infliximab $(5 \mathrm{mg} / \mathrm{kg})$ once every 2 weeks until symptom resolution, followed by a prolonged steroid taper [42]. Prompt recognition, management, and monitoring of grade 2 and higher irAEs are critical for the successful resolution of these toxicities, although such events can often take weeks to months to return to baseline. Algorithms for the management of irAEs with ipilimumab have been published by Fecher et al. [37]. Unfortunately, prophylactic steroids and other preventive strategies to avoid irAEs have not shown clinical benefit to date [37]. An interesting and consistent observation is that a higher incidence of irAEs, particularly grade 3/4 irAEs, has been associated with a higher proportion of patients eventually achieving an objective response [43]. However, as grade 3/4 irAEs can be life threatening, it is recommended that patients experiencing severe irAEs discontinue ipilimumab [20, 37].

\section{Programmed Death-1 (PD-1) and Programmed Death Ligand 1 (PD-L1)}

\subsection{Background}

PD-1 (CD279) is also a co-inhibitory molecule that plays an important role in the balance of tumor immunity and inflammatory reactions [3, 44]. However, in contrast to CTLA-4, PD-1 appears to play a greater role in limiting and modulating the activity of $\mathrm{T}$ cells in peripheral tissues and organs during inflammatory responses in an effort to prevent host tissue damage. PD-1 expression is induced on activated $T$ cells, and the interaction between PD- 1 and one of its ligands-typically PD-L1 (B7-H1, CD274) or PD-L2 (B7-DC, CD273) — on the surface of tumors leads to a diminished antitumor response and has been associated with a poorer patient outcome [44]. High levels of PD-1 expression on antigen-experienced $\mathrm{CD}^{+} \mathrm{T}$ cells are associated with the loss of effector functions, including the ability of T cells to proliferate and express interleukin (IL)- 


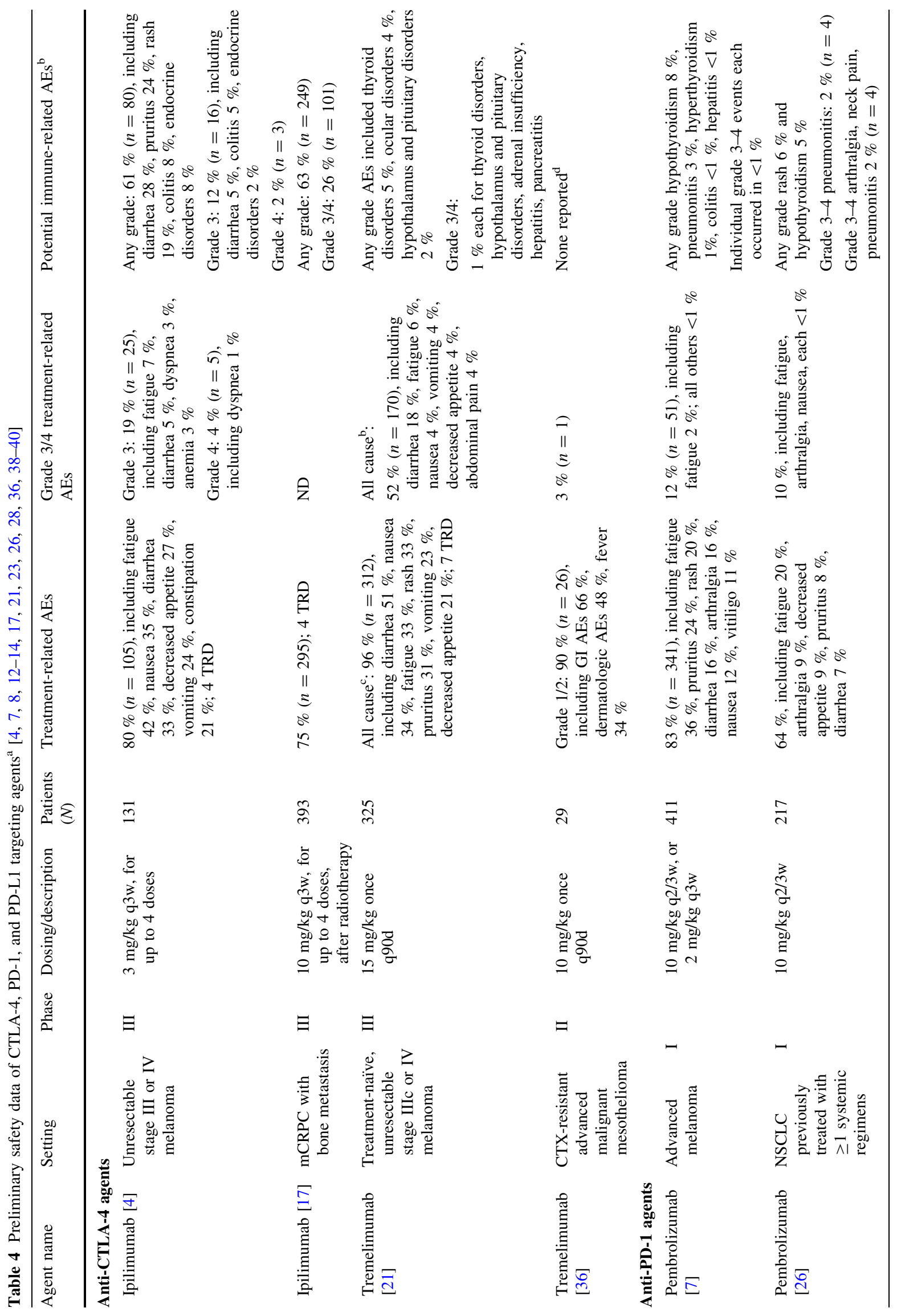




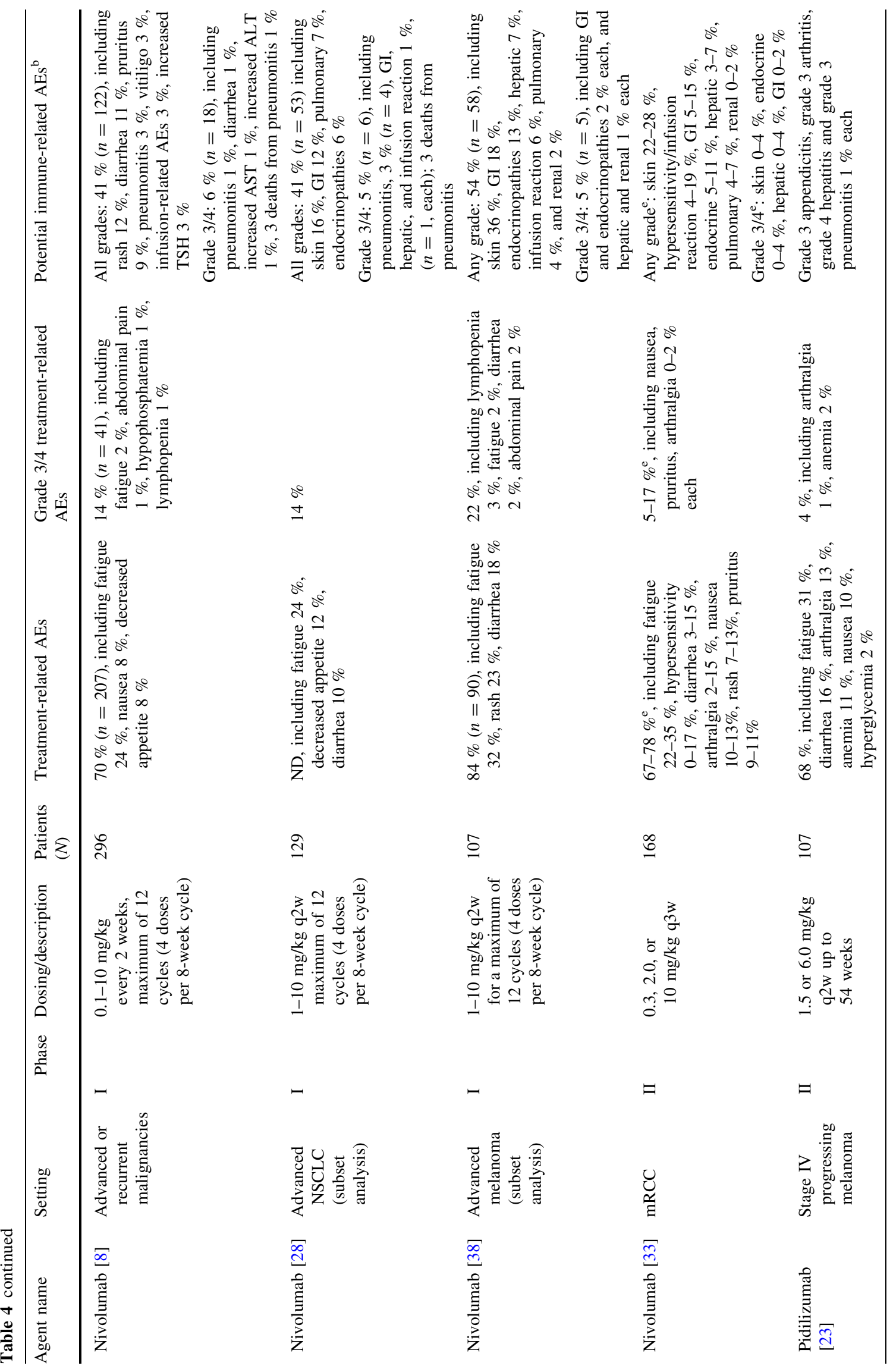




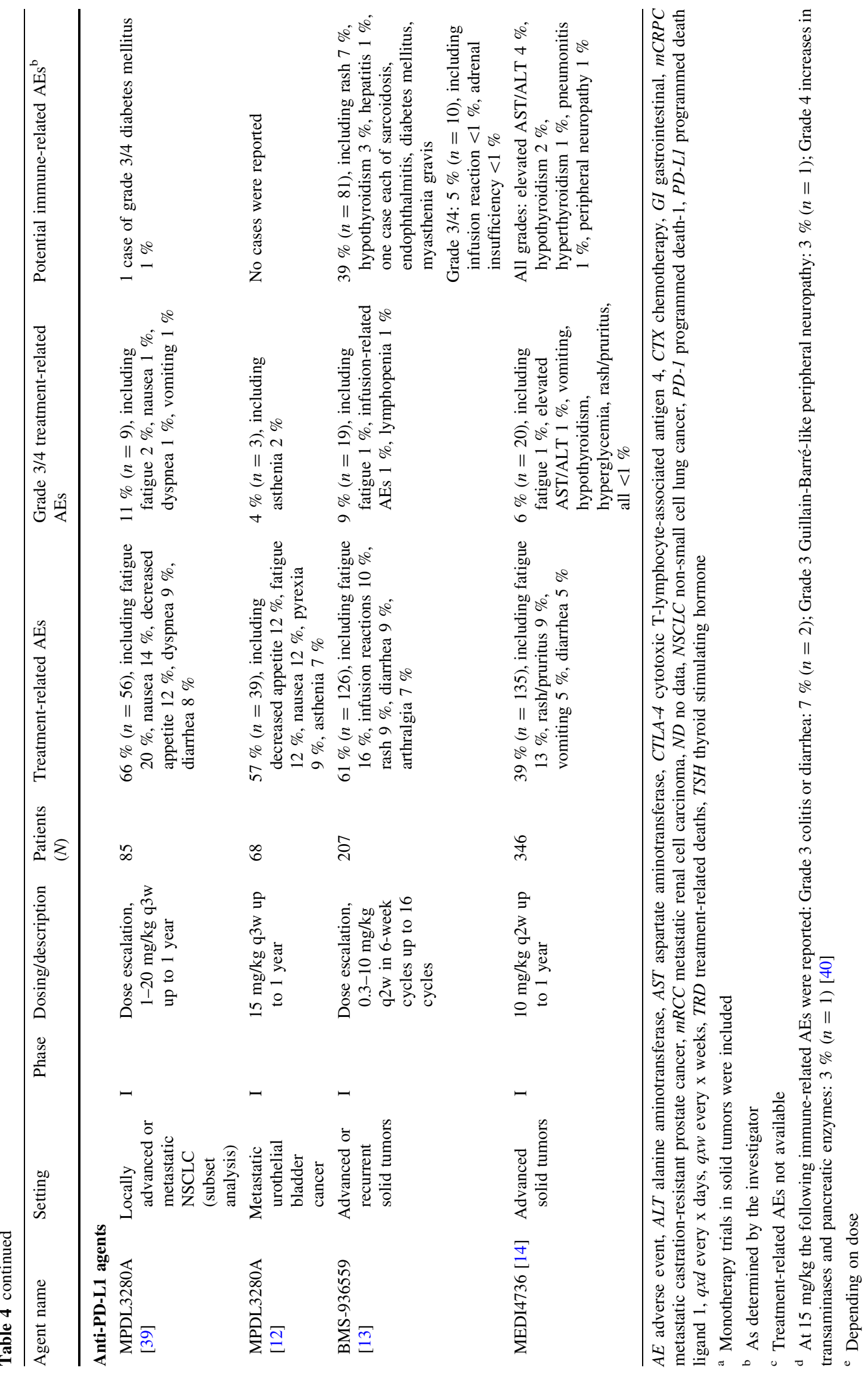


2 , tumor necrosis factor (TNF)- $\alpha$, and interferon (IFN)- $\gamma-$ a process termed T-cell 'exhaustion' or 'tolerance'. In this state, tumor-infiltrating lymphocytes become tolerant and are less capable of carrying out antitumor immune responses as a result of chronic antigen exposure and prolonged negative immune regulation. While both CTLA4 and PD- 1 are immune checkpoint inhibitors, CTLA- 4 is thought to act earlier in the process of T-cell activation, whereas PD-1 plays a role in attenuating T-cell responses later in the process, after $\mathrm{T}$ cells have migrated to the tumor microenvironment [44] (Fig. 2).

Given these observations, both PD-1 and PD-L1 antibody blockade may be a promising target for cancer immunotherapy (Fig. 2) [3, 45]. Anti-PD-1 antibodies are designed to inhibit PD-1 from engaging with any of its ligands, thereby preventing both PD-1:PD-L1 and PD1:PD-L2 binding. In contrast, anti-PD-L1 agents prevent PD-1:PD-L1 binding, but not necessarily PD-1:PD-L2 binding. There is evidence that PD-L1 may bind CD80 (B7-1) on $\mathrm{T}$ cells, leading to a down-regulatory signal; hence, anti-PD-L1 could inhibit this interaction as well [3, 44]. Given the current understanding that PD-1:PD-L1 interactions are a predominant mechanism of tumor immune evasion, whether agents targeting PD-1 versus PD-L1 will have different clinical profiles is unknown.

To date, all data reported for PD-1 pathway inhibitors have been in phase I or II studies without control arms. The ongoing phase II and III trials that include control arms should provide data with greater context. Table 2 lists PFS and OS data from historical controls and studies where these data were available. However, as the studies differ greatly in terms of patient characteristics, study sizes, and length of follow-up, direct comparisons should be made with great caution.

\subsection{Efficacy with PD-1 Inhibitors}

\subsubsection{Pembrolizumab (MK-3475)}

Pembrolizumab (MK-3475) is a humanized IgG4 monoclonal antibody against PD-1 [7] (Table 1 [4-16]). A phase I study, including expansion cohorts, evaluated pembrolizumab treatment in patients with advanced melanoma who had previously received or not received ipilimumab [7]. The overall response rate across all doses was $34 \%$; $88 \%$ of responses were ongoing at the time of analysis and the median duration of response had not been reached. Prior treatment with immunotherapy, including ipilimumab and IL-2, did not preclude activity of pembrolizumab, nor were higher rates of AEs observed in patients who had received previous immunotherapy compared with those who had not. Preliminary survival data of pembrolizumab
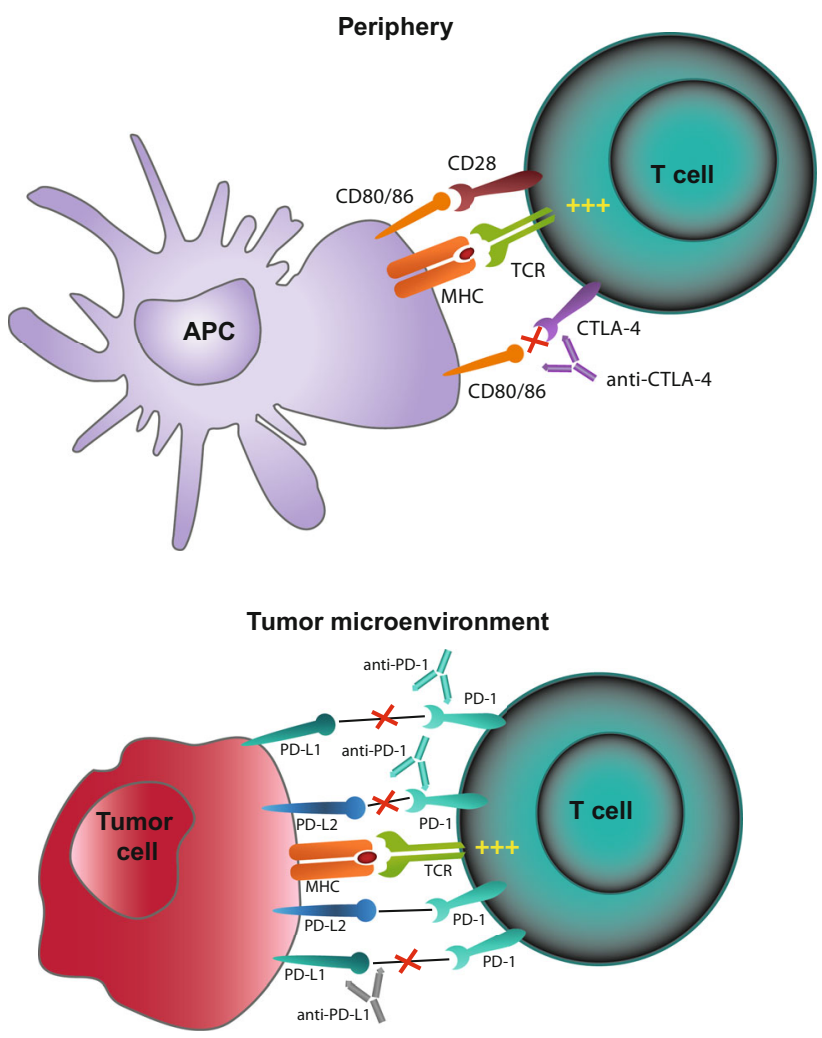

Fig. 2 Inhibiting the CTLA-4 and PD-1 immune checkpoint pathways to restore antitumor immune responses. In peripheral lymphoid organs and tissues, anti-CTLA-4 antibodies block CTLA-4 from binding CD80/86 on APCs and prevent T-cell inhibition. In the tumor microenvironment, PD-L1 and/or PD-L2 expression inhibits PD-1expressing $\mathrm{T}$ cells. Interruption of PD-1:PD-L1 and PD-1:PD-L2 binding by anti-PD-1 antibodies or interruption of PD-1:PD-L1 binding by anti-PD-L1 antibodies restores T-cell immune responses. $A P C$ antigen-presenting cell, CTLA-4 cytotoxic T-lymphocyte-associated antigen $4, M H C$ major histocompatibility complex, $P D-1$ programmed death-1, $P D-L 1$ programmed death ligand $1, P D-L 2$ programmed death ligand 2, TCR T-cell receptor

and other PD-1 pathway agents is listed in Table $2[4,5,7$, 18, 19, 21-33].

Pembrolizumab was also investigated in a phase I study in patients with previously treated NSCLC [25, 26]. Interim data analysis revealed that, in a cohort of 217 patients with NSCLC, the ORR was $18 \%$ based on immune-related response criteria (irRC), and the median OS was 51 weeks. irRC have been used primarily to assess responses in patients with melanoma, and have not been validated in other cancers [46]. Responses were seen in patients with non-squamous and squamous histology, and in current/former and never smokers. [25, 26]. As a firstline therapy for NSCLC, pembrolizumab reported preliminary ORRs of $47 \%$ by irRC. Median PFS was 27 weeks (Response Evaluation Criteria in Solid Tumors [RECIST]) and 37 weeks (irRC) [27]. 
Pembrolizumab also showed antitumor activity in patients with head and neck cancer in a phase I study [47]. Responses were seen in $20 \%$ (11/56) of evaluable patients, which included human papillomavirus-positive and -negative tumors (Table 3 [16]).

\subsubsection{Nivolumab}

Nivolumab (BMS-936558) is a fully human IgG4 PD-1 immune checkpoint inhibitor [8] (Table 1 [4-16]). A phase I, dose-escalating study in multiple tumor types reported objective responses with nivolumab in a substantial portion of patients with melanoma, NSCLC, or renal cell carcinoma (RCC), but no objective responses in patients with colorectal cancer (CRC) or CRPC [8]. In patients with melanoma treated with nivolumab across all doses in the phase I trial, the ORR was $32 \%$ and the median duration of response was 99 weeks. The median OS was 17.3 months and 1-, 2-, and 3-year survival rates were 63, 48 , and $41 \%$, respectively [22] (Table $2[4,5,7,18,19$, 21-33]).

In the phase I trial among patients with NSCLC and across all doses, the ORR was $17 \%$ (22/129), the estimated median response duration was 74 weeks, and overall 1- and 2-year survival rates were 42 and $24 \%$, respectively [28]. Ongoing trials are evaluating nivolumab alone or in combination with chemotherapy, erlotinib, or ipilimumab in patients with chemotherapy-naïve NSCLC, and have reported initial evidence of antitumor activity [29, 48-50]. With first-line nivolumab monotherapy in a phase I trial, the initial ORR was $30 \%$, median PFS was 36.1 weeks, and median OS was not reached (range 13.3-89.1+) in 20 evaluable patients. The 1-year OS rate was $75 \%$ [29].

In phase II study in patients with previously-treated RCC, the overall response rate was $21 \%(35 / 168)$, with the majority of responses lasting $>1$ year [33]. Across the evaluated doses, the PFS ranged from 2.7 to 4.2 months, and the median OS ranged from 18.2 to 24.7 months. The survival rate was approximately $35 \%$ at 2.5 years [33] (Table 2 [4, 5, 7, 18, 19, 21-33]). Phase II and III trials of nivolumab are ongoing in melanoma, NSCLC, RCC, and squamous head and neck cancer (Table 3 [16]).

\subsubsection{Pidilizumab (CT-011)}

Pidilizumab (CT-011) is a humanized anti-PD-1 IgG1 monoclonal antibody [9] (Table 1 [4-16]). Pidilizumab was evaluated in patients with stage IV melanoma in a phase II open-label study. The ORR using irRC was $6 \%$, the median PFS was 1.9 months, and the 1-year survival rate was $65 \%$ [23] (Table 2 [4, 5, 7, 18, 19, 21-33]).

Pidilizumab has also shown evidence of efficacy in patients with hematologic malignancies [51]. Separately, pidilizumab after autologous hematopoietic stem-cell transplantation (AHSCT) was evaluated in a phase II trial in patients with diffuse large B-cell lymphoma (DLBCL) or primary mediastinal large B-cell lymphoma [9]. A total of 66 patients completed all treatment cycles, and PFS at 16 months from the start of treatment was $72 \%$. This compares favorably with the PFS rate at 18 months of $52 \%$ in a historical group of patients with DLBCL with similar characteristics (i.e., would have met the eligibility criteria for the study, including no progression or relapse within 2 months of AHSCT) who had received high-dose chemotherapy followed by AHSCT $[9,52]$. Among the 35 patients with measurable disease after transplant, the overall response rate with pidilizumab treatment was $51 \%$, and the complete remission rate was $34 \%$ [9].

\subsubsection{AMP-224}

AMP-224 is a recombinant fusion protein comprising the extracellular domain of PD-L2 and the Fc region of human IgG [10] (Table 1 [4-16]). This agent is designed to bind PD-1, and preclinical studies suggest its mechanism of action may differ from monoclonal antibody blockade. A phase I trial evaluating the safety of AMP-224 in patients with advanced cancer is ongoing (NCT01352884) [53]. Infusion reactions were common, occurring in $69 \%$ of patients across dose cohorts. It is unclear whether this study is moving forward, as a high rate of infusion reactions and lack of efficacy have been observed compared with other PD-1 inhibitors.

\subsection{Safety of PD-1 Inhibitors}

While no head-to-head trials have been conducted, the safety profiles of the anti-PD-1 agents seem to be generally similar. In the largest and most mature studies of pembrolizumab and nivolumab, grade 3/4 treatment-related AEs were reported in 10-22 \% of patients [7, 8, 26, 38]. The most common treatment-related $\mathrm{AE}$ was fatigue in all studies $(20-36 \%$ all grades, $2 \%$ grade $3 / 4)$. Potential immune-related select AEs were also commonly reported: dermatologic toxicities (pruritus $\leq 24 \%$ all grades, $<1 \%$ grade $3 / 4$; rash $6-20 \%$ all grades, $<1 \%$ grade $3 / 4$; vitiligo $\leq 11 \%$ all grades, $0 \%$ grade $3 / 4$ ), gastrointestinal toxicities (diarrhea $7-16 \%$ all grades, $\leq 1 \%$ grade $3 / 4$; nausea $6-12 \%$ all grades, $<1 \%$ grade $3 / 4$ ), and endocrinopathies (hypothyroidism 2-8 \% all grades, $<1 \%$ grade 3/4; hyperthyroidism 1-2\% all grades, $<1 \%$ grade $3 / 4)$. Arthralgia (all grades) was reported in $4-16 \%$ of patients, and grade $3 / 4$ in $<1 \%$. Pneumonitis of all grades was noted in $3 \%$ of pembrolizumab- or nivolumab-treated patients, with $\leq 1 \%$ of patients developing grade $3 / 4$ pneumonitis. Although rare, three deaths due to 
pneumonitis in nivolumab-treated patients are concerning. Nivolumab or pembrolizumab in patients who had received prior ipilimumab showed similar safety profiles to those of ipilimumab-naïve patients, supporting the sequential use of these therapies $[54,55]$.

\subsection{Efficacy with PD-L1 Inhibitors}

\subsubsection{MPDL3280A}

MPDL3280A is a human anti-PD-L1 monoclonal antibody $[11,12]$ (Table 1 [4-16]). MPDL3280A is being assessed in a dose-ranging phase I study in patients with multiple tumor types. Interim results from 53 evaluable patients with NSCLC revealed an ORR of $23 \%$ in patients across squamous and non-squamous histologies, including several patients with rapid tumor shrinkage [39]. Some patients (not included in the ORR) had delayed responses after apparent radiographic progression. Most responses were ongoing at the time of analysis. The ORR in patients with RCC was $13 \%$; durable responses were seen in patients with clear cell and non-clear cell disease [11]. In patients with urothelial bladder cancer, the ORR was $25 \%(17 / 67)$ [12]. Phase II and III trials evaluating MPDL3280A in advanced lung cancer, advanced RCC, and urothelial bladder cancer are ongoing (Table 3 [16]).

\subsubsection{BMS-936559}

BMS-936559 is a fully human IgG4 monoclonal antibody directed against PD-L1 [13] (Table 1 [4-16]). The safety and activity of BMS-936559 was assessed in a phase I dose-escalating study in patients with advanced solid tumors [13]. Clinical activity was observed in patients with melanoma, NSCLC, RCC, CRC, ovarian, or pancreatic cancer, but not for patients with gastric or breast cancer. ORRs for patients with melanoma, NSCLC, RCC, and ovarian cancer were $17,10,12$, and $6 \%$, respectively, and responses lasted for $\geq 1$ year in 8 of 16 patients with at least 1 year of follow-up. No additional trials of BMS936559 are currently listed in ClinicalTrials.gov [16].

\subsubsection{MEDI4736}

MEDI4736 is a human IgG1 monoclonal antibody that binds PD-L1 [14] (Table 1 [4-16]). MEDI4736 is being investigated in multiple tumor types, including melanoma, NSCLC, squamous head and neck cancer, and pancreatic cancer in a phase I trial. A preliminary analysis reported ORRs of $13 \%$ (6/47) in patients with NSCLC and $14 \%$ (3/ 22 ) in patients with squamous head and neck cancer, and evidence of activity against pancreatic and gastroesophageal cancer [14]. Numerous studies of MEDI4736 are planned or ongoing in patients with NSCLC or other malignancies (Table 3 [16]).

\subsection{Safety of PD-L1 Inhibitors}

The types of AEs reported with PD-L1 agents seem similar to those targeting PD-1, but the incidence of AEs appears to be lower. The reported rate of grade 3/4 treatmentrelated AEs across studies and tumor types ranged from 4 to $13 \%[11-14,39]$. Fatigue $(12-20 \%$ all grades, $0-2 \%$ grade 3/4), gastrointestinal AEs (diarrhea 5-9 \% all grades, $0 \%$ grade $3 / 4$; nausea $6-14 \%$ all grades, $0-1 \%$ grade 3/4), dermatologic AEs (rash 7-9 \% all grades, $<1 \%$ grade $3 / 4$; pruritus $6 \%$ all grades, $<1 \%$ grade $3 / 4$ ), and endocrinopathies (hypothyroidism $2-3 \%$ all grades, $<1 \%$ grade 3/4) were the most common.

BMS-936559 had a higher reported rate of infusionrelated reactions $(10 \%$ all grades, $\leq 1 \%$ grade $3 / 4)$ and arthralgia (7\% all grades, $0 \%$ grade $3 / 4$ ) than other PDL1-targeting agents [13] (Table 4 [4, 7, 8, 12-14, 17, 21, $23,26,28,36,38-40])$.

\subsection{PD-L1 as a Predictive Biomarker}

Emerging evidence suggests that PD-L1 expression on pretreatment tumor specimens may be a predictive biomarker of efficacy with PD-1 pathway inhibitors. Across agents, studies, and tumor types, antitumor activity was generally higher against PD-L1-positive tumors versus tumors with low or negative staining for PD-L1 (Table 5 [11, 12, 14, 22, 28, 29, 39, 56-59]). However, the methodology, amount of staining (or 'cut-off') required to qualify as a PD-L1-positive tumor and timing of sample collection (archival or immediately pre-treatment) varied across studies. Thus, while these preliminary findings are encouraging, data on tumor PD-L1 expression as a potential predictive biomarker are evolving, and prospective validation will be needed.

\section{Immunotherapy Clinical Response Patterns}

Across the various immunotherapy clinical development programs, investigators have observed response patterns that sometimes differ from the conventional responses observed with cytotoxic agents. Standard response criteria may not capture or adequately describe the responses produced by novel immunotherapy; thus, clinical trials may not always capture the full clinical benefit to patients who receive immunotherapy. To better characterize this pattern of response, new irRC were created that accounted for antitumor response based on total measurable tumor burden as measured by the sum of index lesions and new 
Table 5 PD-L1 expression and association with clinical activity [11, 12, 14, 22, 28, 29, 39, 56-59]

\begin{tabular}{|c|c|c|c|c|c|c|c|}
\hline Agent & Setting & $\begin{array}{l}\text { Cut-off for } \\
\text { PD-L1 }{ }^{+a}\end{array}$ & $\begin{array}{l}\text { ORR in pts with } \\
\text { PD-L1 } 1^{+} \text {tumors, } \\
\%(n / N)\end{array}$ & $\begin{array}{l}\text { ORR in pts with } \\
\text { PD-L1 } 1^{-} \text {low/ } \\
\text { negative tumors, } \\
\%(n / N)\end{array}$ & $\begin{array}{l}\text { Median PFS } \\
\text { in pts with } \\
\text { PD-L1 }{ }^{+} \\
\text {tumors }\end{array}$ & $\begin{array}{l}\text { Median PFS } \\
\text { in pts with } \\
\text { PD-L1 } 1^{-} \text {low/ } \\
\text { negative tumors }\end{array}$ & Reference(s) \\
\hline Pembrolizumab & Advanced melanoma & $\geq 1 \%^{\mathrm{b}}$ & 51 (ND) & 6 (ND) & 12 months & 3 months & {$[56]$} \\
\hline Pembrolizumab & Advanced NSCLC & $\geq 50 \%^{\mathrm{b}}$ & $37(15 / 41)$ & $11(10 / 88)$ & 14.0 weeks & 9.3 weeks & {$[57]$} \\
\hline Nivolumab & $\begin{array}{l}\text { Previously-treated } \\
\text { melanoma }\end{array}$ & $\geq 5 \%^{\mathrm{b}}$ & $44(8 / 18)$ & $13(3 / 23)$ & 9 months & 2 months & [22] \\
\hline Nivolumab & $\begin{array}{l}\text { Previously-treated } \\
\text { NSCLC }\end{array}$ & $\geq 5 \%^{\mathrm{b}}$ & $15(5 / 33)$ & $14(5 / 35)$ & 3.6 months & 1.8 months & [28] \\
\hline Nivolumab & CTX-naïve NSCLC & $\geq 5 \%^{\mathrm{b}}$ & $50(5 / 10)$ & $0(0 / 7)$ & 45.6 weeks & 36.1 weeks & [29] \\
\hline Nivolumab & $\mathrm{RCC}$ & $\geq 5 \%^{\mathrm{b}}$ & $22(4 / 18)$ & $8(3 / 38)$ & ND & ND & [58] \\
\hline MPDL3280A & $\begin{array}{l}\text { Previously-treated } \\
\text { NSCLC }\end{array}$ & $\begin{array}{l}\text { Score }=3 \\
(\text { highly } \\
\text { positive) }^{\mathrm{c}}\end{array}$ & $83(5 / 6)$ & $20(4 / 20)$ & ND & ND & {$[39,59]$} \\
\hline MPDL3280A & $\mathrm{RCC}$ & $\begin{array}{l}\text { Positive } \\
\text { staining }\end{array}$ & $20(2 / 10)$ & $10(2 / 21)$ & ND & ND & {$[11,59]$} \\
\hline MPDL3280A & $\begin{array}{l}\text { Urothelial bladder } \\
\text { cancer }\end{array}$ & $\geq 5 \%$ & 43 (ND) & 11 (ND) & ND & ND & [12] \\
\hline MEDI4736 & NSCLC & Undefined & $39(5 / 13)$ & $5(1 / 19)$ & ND & ND & [14] \\
\hline MEDI4736 & $\begin{array}{l}\text { Head and neck } \\
\text { cancer }\end{array}$ & Undefined & $50(2 / 4)$ & $6(1 / 16)$ & ND & ND & [14] \\
\hline
\end{tabular}

$C T X$ chemotherapy, $N D$ no data, $N S C L C$ non-small cell lung cancer, $R C C$ renal cell carcinoma, $P D-L 1$ programmed death ligand 1 , pts patients

a Amount of staining required to qualify as a $\mathrm{PD}-\mathrm{L1}^{+}$tumor

b Membrane staining of tumor cells

c Staining of tumor-infiltrating immune cells; amount of staining to qualify as a PD-L1 ${ }^{+}$tumor was not defined

d Staining of tumor-infiltrating immune cells

measurable lesions [46]. Time point response assessment was also incorporated into the criteria, as two observations at least 4 weeks apart were necessary to help distinguish progression from 'pseudoprogression', in which there is an initial increase in tumor size followed by tumor shrinkage. The differences between World Health Organization (WHO) criteria and the new irRC are listed in Table 6 [46].

It has also been determined that some of these new response patterns to immune therapies are associated with a favorable survival outcome and may include the following:

- Stable disease, which in some cases may be followed by slow and steady decline of tumor burden. Durable, stable disease lasting months or even years has been observed in some patients.

- Reduction after an initial increase in tumor burden; this observation has been associated with T-cell infiltration into the tumor, giving the appearance of progressive disease.

- Reduction in total tumor burden during or after the appearance of new lesions, possibly due to the unique mechanism of action of immunotherapy, as the activated immune system may take some time to mount an effective antitumor response.
Time to response appears to be faster for agents that block PD-1 or PD-L1 compared with the many weeks it may take to observe tumor shrinkage in response to antiCTLA-4 treatment $[8,13,21,38,46]$. Additionally, response rates in patients given anti-PD-1 or anti-PD-L1 treatment may be higher than in those receiving antiCTLA-4, although head-to-head trial data are not yet available.

\section{Other Immune Targets-Inhibitory and Stimulatory}

In addition to CTLA-4 and PD-1, other classes of inhibitory and stimulatory molecules have potential to be used as anticancer immunotherapy. One inhibitory molecule that has drawn much attention recently is lymphocyte activation gene-3 (LAG-3), a CD4 homolog that binds to MHC class II molecules (Fig. 1). LAG-3 is expressed on activated $\mathrm{CD}^{+}{ }^{+}$and $\mathrm{CD}^{+}{ }^{+} \mathrm{T}$ cells, as well as $\mathrm{B}$ cells, natural killer cells, and tumor-infiltrating lymphocytes, and is thought to negatively regulate $\mathrm{T}$-cell expansion by limiting $\mathrm{T}$-cell activation. However, LAG-3 knockout mice do not develop overt autoimmunity, suggesting that it plays a more subtle role in regulating $\mathrm{T}$-cell function than the checkpoint 
Table 6 Comparison between WHO criteria and the irRC [46]

\begin{tabular}{|c|c|c|}
\hline & WHO & irRC \\
\hline $\begin{array}{l}\text { New, measurable } \\
\text { lesions (i.e., } \\
\geq 5 \times 5 \mathrm{~mm} \text { ) }\end{array}$ & Always represent PD & Incorporated into tumor burden \\
\hline $\begin{array}{l}\text { New, non- } \\
\text { measurable lesions } \\
\text { (i.e., }<5 \times 5 \mathrm{~mm})\end{array}$ & Always represent PD & Do not define progression (but preclude irCR) \\
\hline Non-index lesions & Changes contribute to defining BOR of CR, PR, SD, and PD & $\begin{array}{l}\text { Contribute to defining irCR (complete disappearance } \\
\text { required) }\end{array}$ \\
\hline CR & $\begin{array}{l}\text { Disappearance of all lesions in two consecutive observations } \\
\text { not less than } 4 \text { weeks apart }\end{array}$ & $\begin{array}{l}\text { Disappearance of all lesions in two consecutive } \\
\text { observations not less than } 4 \text { weeks apart }\end{array}$ \\
\hline PR & $\begin{array}{l}\geq 50 \% \text { decrease in SPD of all index lesions vs. baseline in } \\
\text { two observations at least } 4 \text { weeks apart, in absence of new } \\
\text { lesions or unequivocal progression of non-index lesions }\end{array}$ & $\begin{array}{l}\geq 50 \% \text { decrease in tumor burden vs. baseline in two } \\
\text { observations at least } 4 \text { weeks apart }\end{array}$ \\
\hline SD & $\begin{array}{l}50 \% \text { decrease in SPD vs. baseline cannot be established nor } \\
25 \% \text { increase vs. nadir, in absence of new lesions or } \\
\text { unequivocal progression of non-index lesions }\end{array}$ & $\begin{array}{l}50 \% \text { decrease in tumor burden vs. baseline cannot be } \\
\text { established nor } 25 \% \text { increase vs. nadir }\end{array}$ \\
\hline PD & $\begin{array}{l}\text { At least } 25 \% \text { increase in SPD vs. nadir and/or unequivocal } \\
\text { progression of non-index lesions and/or appearance of new } \\
\text { lesions (at any single time point) }\end{array}$ & $\begin{array}{l}\text { At least } 25 \% \text { increase in tumor burden vs. nadir (at any } \\
\text { single time point) in two consecutive observations at } \\
\text { least } 4 \text { weeks apart }\end{array}$ \\
\hline
\end{tabular}

Reproduced with permission from Wolchok et al. [46]

$B O R$ best overall response, $C R$ complete response, ir $C R$ immune-related complete response, $P D$ progressive disease, $P R$ partial response, $S D$ stable disease, $S P D$ sum of the products of the two largest perpendicular diameters, WHO World Health Organization

molecules CTLA-4 and PD-1 [3, 60]. While LAG-3 is another immune checkpoint that may be important in the immune response to cancer, blockade of this pathway has not been clinically evaluated to the same extent as the CTLA-4 and PD-1 pathways [3]. However, based on the success of other checkpoint molecules as targets for anticancer therapy, research is now ongoing to assess the possible clinical value of LAG-3 blockade. IMP321 is a soluble LAG-3 Ig fusion protein and MHC class II agonist (Table 1 [4-16]); it has been combined with gemcitabine in a phase I study in patients with advanced pancreatic adenocarcinoma [15]. IMP321 plus gemcitabine appears to be a well tolerated regimen that has not resulted in any serious AEs in patients to date; however, limited antitumor responses were attributed to the low doses of IMP321. A small study combining IMP321 and melanoma-associated antigen immunization in patients with melanoma is ongoing (NCT01308294).

A variety of other molecules that similarly regulate T-cell activation, tolerance/exhaustion, anergy, and even T-cell death are currently being assessed as potential targets for anticancer therapy. One of these inhibitory molecules is T-cell immunoglobulin and mucin domain 3 (TIM3), which is a member of the TIM family (Fig. 1). TIM3 is expressed by IFN- $\gamma$-secreting helper $\mathrm{T}\left(\mathrm{T}_{\mathrm{H}} 1\right)$ cells, as well as dendritic cells, monocytes, and $\mathrm{T}$ cells [61]. When bound to its ligand, galectin-9, TIM 3 induces $T_{H} 1$ cell death [62]. Studies of TIM3-deficient mice suggest that the TIM3 pathway inhibits the expansion and effector functions of $T_{H} 1$ cells and may be important for tolerance induction of $\mathrm{T}_{\mathrm{H}} 1$ cells [63]. Administration of a TIM3 fusion protein resulted in hyperproliferation of $\mathrm{T}_{\mathrm{H}} 1$ cells and inflammatory cytokine release, suggesting a ligand for TIM3 is also expressed by these cells.

Glucocorticoid-induced TNF receptor-related gene (GITR) can provide a co-stimulatory signal to both $\mathrm{CD} 4^{+}$and $\mathrm{CD}^{+}$-naïve T-cells, particularly when T-cell receptor stimulation is weak [64] (Fig. 1). T cells that do not express GITR are more prone to activation-induced cell death, suggesting that GITR-mediated stimulation may enhance the survival of activated $\mathrm{T}$ cells. Also, preclinical studies showed that agonist anti-GITR antibodies could reverse regulatory $\mathrm{T}$-cell suppression of effector $\mathrm{T}$ cells. Data from murine models suggest that GITR blockade may be most effective when combined with melanoma vaccination strategies and not as monotherapy [65]. Currently, a phase I dose-escalation trial of an anti-GITR monoclonal antibody (TRX518) is recruiting patients with unresectable stage III or IV melanoma or other solid tumor malignancies (NCT01239134).

\section{Combination Strategies}

Despite promising results as monotherapies, there remains a clear need to increase the number of patients with malignancies that can benefit from immune checkpoint inhibitors. The increasing arsenal of targeted and immune- 
based therapies affords opportunities for sequencing and combination strategies to improve outcomes. Indeed, rapid and deep tumor regression was observed in a substantial number of patients when the CTLA-4 inhibitor, ipilimumab, was administered concurrently with nivolumab [24]. In this study, $42 \%$ of patients had $\geq 80 \%$ tumor reduction at 36 weeks, and 1- and 2-year survival rates were 85 and $79 \%$, respectively. Though the efficacy appeared to be increased as compared with either drug alone, so did the rate of AEs. The observed toxicities were similar to those reported with monotherapy, albeit with higher incidence, including $62 \%$ of patients experiencing grade 3/4 AEs. Other anti-CTLA-4 plus anti-PD-1 trials are ongoing, as are trials exploring dual blockade of the PD-1 pathway (anti-PD-1 plus anti-PD-L1) [16]. Additional trials that are planned or have already entered the clinic include combinations of PD-1 pathway inhibitors with LAG-3, indolamine 2,3-dioxygenase 1 (IDO1), sipuleucel$\mathrm{T}$, or other vaccinations. Immune checkpoint inhibitor combinations with T-cell agonists (i.e., anti-CD40, antiCD27, and anti-4-1BB) and with other immunostimulants (i.e., IFN, IL-21, and anti-killer immunoglobulin-like receptor $[\mathrm{KIR}]$ ) are also underway.

It has been postulated that targeted agents and/or cytotoxic chemotherapy that effectively destroy tumor cells may increase circulating tumor antigens and, therefore, increase the immunogenic response and utility of checkpoint inhibitors [35]. In fact, inhibition of mitogen-activated protein kinase with BRAF and/or MEK inhibitors in melanoma cells has been shown to modulate the functions of immune cells in preclinical studies [66]. While a phase I/II study (NCT01400451) evaluating the safety and efficacy of combining vemurafenib with ipilimumab recently closed due to hepatic toxicity, a phase II study of vemurafenib followed by sequential ipilimumab in patients with V600 BRAF-mutated melanoma is still ongoing. Initial reports from phase I trials combining nivolumab with vascular endothelial growth factor (VEGF)-targeted therapies (sunitinib or pazopanib) are currently under study to determine the best dose and schedule [67, 68]. A combination regimen of pidilizumab $(3 \mathrm{mg} / \mathrm{kg})$ plus rituximab $\left(375 \mathrm{mg} / \mathrm{m}^{2}\right)$ has also been investigated in a phase II trial in patients with relapsed follicular lymphoma. Of 29 patients evaluable for efficacy, 19 had an objective response (66\%), 15 had a complete response (52\%), and four had a partial response (14\%) [69].

Trials using ipilimumab combined with various cytotoxic chemotherapies, such as temozolomide plus doxycycline (NCT01590082) or fotemustine (NCT01654692) are underway in patients with metastatic melanoma, as are numerous trials of PD-1 pathway inhibitors plus chemotherapy or targeted agents [16]. Trials evaluating ipilimumab plus paclitaxel/carboplatin (NCT01165216) and pembrolizumab or nivolumab plus chemotherapy or targeted agents (NCT02039674; NCT01454102) have been started in patients with NSCLC. Details on ongoing phase II and III trials investigating combination regimens with immune checkpoint inhibitors are provided in Table 3 [16].

\section{Conclusion}

A better understanding of tumor immunology and immunotherapy, both at the bench and at the bedside, has led to a new and promising area of basic and clinical cancer research. Inhibitors of immune checkpoint regulators have in some cases led to deep and durable responses in patients with advanced malignancies. Many of the observed side effects are manageable and reversible following standard protocols.

Lessons learned from CTLA-4 and PD-1 blockade, in both the laboratory and the clinic, not only provide the foundation for a future era of superior immune checkpoint inhibition, but also provide a nidus of questions that remain unanswered. Furthering Virchow's initial observation and our understanding of the link between the immune system and malignancy, immune checkpoint inhibitors appear to offer new hope for cancer patients.

Acknowledgments The authors take full responsibility for the content of this publication and confirm that it reflects their viewpoint and expertise. Professional medical writing assistance was provided by Britt Anderson, Ph.D., and professional editing assistance was provided by Karin McGlynn at StemScientific and was funded by Bristol-Myers Squibb. Neither Bristol-Myers Squibb nor StemScientific influenced the content of the manuscript, nor did the author receive financial compensation for authoring the manuscript.

The manuscript does not contain original clinical studies or patient data that have not been published or presented elsewhere.

Drs. Shih, Arkenau, and Infante have no conflicts of interest to declare.

Open Access This article is distributed under the terms of the Creative Commons Attribution Noncommercial License which permits any noncommercial use, distribution, and reproduction in any medium, provided the original author(s) and the source are credited.

\section{References}

1. Balkwill F, Mantovani A. Inflammation and cancer: back to Virchow? Lancet. 2001;357(9255):539-45.

2. Bour-Jordan $\mathrm{H}$, Esensten $\mathrm{JH}$, Martinez-Llordella M, et al. Intrinsic and extrinsic control of peripheral T-cell tolerance by costimulatory molecules of the CD28/ B7 family. Immunol Rev. 2011;241(1):180-205.

3. Pardoll DM. The blockade of immune checkpoints in cancer immunotherapy. Nat Rev Cancer. 2012;12(4):252-64.

4. Hodi FS, O'Day SJ, McDermott DF, et al. Improved survival with ipilimumab in patients with metastatic melanoma. N Engl J Med. 2010;363(8):711-23. 
5. Robert C, Thomas L, Bondarenko I, et al. Ipilimumab plus dacarbazine for previously untreated metastatic melanoma. N Engl J Med. 2011;364(26):2517-26.

6. Kirkwood JM, Lorigan P, Hersey P, et al. Phase II trial of tremelimumab $(\mathrm{CP}-675,206)$ in patients with advanced refractory or relapsed melanoma. Clin Cancer Res. 2010;16(3):1042-8.

7. Ribas A, Hodi FS, Kefford R, et al. Efficacy and safety of the anti-PD-1 monoclonal antibody MK-3475 in 411 patients (pts) with melanoma (MEL). J Clin Oncol. 2014;32(18 suppl):abstr LBA9000. http://meetinglibrary.asco.org/content/133842-144. Accessed 1 July 2014.

8. Topalian SL, Hodi FS, Brahmer JR, et al. Safety, activity, and immune correlates of anti-PD-1 antibody in cancer. N Engl J Med. 2012;366(26):2443-54.

9. Armand P, Nagler A, Weller EA, et al. Disabling immune tolerance by programmed death-1 blockade with pidilizumab after autologous hematopoietic stem-cell transplantation for diffuse large B-cell lymphoma: results of an international phase II trial. J Clin Oncol. 2013;31(33):4199-206.

10. Smothers JF, Hoos A, Langermann S, et al. AMP-224, a fusion protein that targets PD-1. Ann Oncol. 2013;24(1 suppl):abstr L02.04. http://annonc.oxfordjournals.org/content/24/suppl_1/i7. 6.full. Accessed 3 March 2014.

11. Cho D, Sosman J, Sznol M, et al. Clinical activity, safety and biomarkers of MPDL3280A, an engineered PD-L1 antibody in patients with metastatic renal cell carcinoma (RCC). J Clin Oncol. 2013;31(15 suppl):abstr 4505. http://meetinglibrary.asco. org/content/115491-132. Accessed 1 July 2014.

12. Powles T, Vogelzang NJ, Fine GD, et al. Inhibition of PD-L1 by MPDL3280A and clinical activity in pts with metastatic urothelial bladder cancer (UBC). J Clin Oncol. 2014;32(15 suppl):abstr 5011. http://meetinglibrary.asco.org/content/128960-144. Accessed 1 July 2014.

13. Brahmer JR, Tykodi SS, Chow LQ, et al. Safety and activity of anti-PD-L1 antibody in patients with advanced cancer. N Engl J Med. 2012;366(26):2455-65.

14. Segal NH, Antonia SJ, Brahmer JR, et al. Preliminary data from a multi-arm expansion study of MEDI4736, an anti-PD-L1 antibody. J Clin Oncol. 2014;32(15 suppl):abstr 3002. http://meetinglibrary. asco.org/content/134136-144. Accessed 1 July 2014.

15. Wang-Gillam A, Plambeck-Suess S, Goedegebuure P, et al. A phase I study of IMP321 and gemcitabine as the front-line therapy in patients with advanced pancreatic adenocarcinoma. Invest New Drugs. 2013;31(3):707-13.

16. ClinicalTrials.gov. 2014. http://clinicaltrials.gov. Accessed 7 July 2014.

17. Kwon ED, Drake CG, Scher HI, et al. Ipilimumab versus placebo after radiotherapy in patients with metastatic castration-resistant prostate cancer that had progressed after docetaxel chemotherapy (CA184-043): a multicentre, randomised, double-blind, phase 3 trial. Lancet Oncol. 2014;15(7):700-12.

18. Lynch TJ, Bondarenko I, Luft A, et al. Ipilimumab in combination with paclitaxel and carboplatin as first-line treatment in stage IIIB/IV non-small-cell lung cancer: results from a randomized, double-blind, multicenter phase II study. J Clin Oncol. 2012;30(17):2046-54.

19. Schadendorf D, Hodi FS, Robert C, et al. Pooled analysis of longterm survival data from phase II and phase III trials of ipilimumab in metastatic or locally, advanced, unresectable melanoma. In: Presented at ESMO 2013. Abstract 24LBA. http:// eccamsterdam2013.ecco-org.eu/Scientific-Programme/Abstractsearch.aspx\#. Accessed 3 March 2014.

20. Yervoy ${ }^{\circledR}$ (ipilimumab) prescribing information. Bristol-Myers Squibb Company, Princeton. 2013.

21. Ribas A, Kefford R, Marshall MA, et al. Phase III randomized clinical trial comparing tremelimumab with standard-of-care chemotherapy in patients with advanced melanoma. J Clin Oncol. 2013;31(5):616-22.

22. Hodi FS, Sznol M, Kluger HM, et al. Long-term survival of ipilimumab-naïve patients (pts) with advanced melanoma (MEL) treated with nivolumab (anti-PD-1; BMS-936558; ONO-4538) in a phase I trial. J Clin Oncol. 2014;32(15 suppl):abstr 9002. http://meetinglibrary.asco.org/content/125578-144. Accessed 1 July 2014.

23. Atkins MB, Kudchadkar RR, Sznol M, et al. Pidilizumab in metastatic melanoma: results from a multicenter phase II, openlabel, randomized trial. J Clin Oncol. 2014;32(15 suppl):abstr 9001. http://meetinglibrary.asco.org/content/131463-144. Accessed 1 July 2014.

24. Sznol M, Kluger H, Callahan MK, et al. Survival, response duration, and activity by BRAF mutation (MT) status of nivolumab (NIVO, anti-PD-1, BMS-936558, ONO-4538) and ipilimumab (IPI) concurrent therapy in advanced melanoma (MEL). J Clin Oncol. 2014;32(15 suppl):abstr LBA9003. http://meetinglibrary.asco.org/content/126008-144. Accessed 1 July 2014.

25. Garon EB, Balmanoukian A, Hamid O, et al. Preliminary clinical safety and activity of MK-3475 monotherapy for the treatment of previously treated patients with non-small cell lung cancer (NSCLC). WCLC. 2013. Abstract MO18.02. https://www. webges.com/cview/library/wclc/home. Accessed 3 March 2014.

26. Garon EB, Leighl NB, Rizvi NA, et al. Safety and clinical activity of MK-3475 in previously treated patients (pts) with nonsmall cell lung cancer (NSCLC). J Clin Oncol. 2014;32(15 suppl): abstr 8020. http://meetinglibrary.asco.org/content/133339-144. Accessed 1 July 2014.

27. Rizvi NA, Garon EB, Patnaik A, et al. Safety and clinical activity of MK-3475 as initial therapy in patients with advanced non-small cell lung cancer (NSCLC). J Clin Oncol. 2014;32(15 suppl):abstr 8007. http://meetinglibrary.asco.org/content/132675144. Accessed 1 July 2014.

28. Brahmer J, Horn L, Gandhi L, et al. Nivolumab (anti-PD-1, BMS-936558, ONO-4538) in patients (pts) with advanced nonsmall-cell lung cancer (NSCLC): survival and clinical activity by subgroup analysis. J Clin Oncol. 2014;32(15 suppl):abstr 8112. http://meetinglibrary.asco.org/content/125774-144. Accessed 1 July 2014.

29. Gettinger S, Shepherd FA, Antonia SJ, et al. First-line nivolumab (anti-PD-1; BMS-936558, ONO-4538) monotherapy in advanced NSCLC: safety, efficacy and correlation of outcomes with PD-L1 status. J Clin Oncol. 2014;32(15 suppl):abstr 8024. http:// meetinglibrary.asco.org/content/125774-144. Accessed 1 July 2014.

30. Motzer RJ, Escudier B, Tomczak P, et al. Axitinib versus sorafenib as second-line treatment for advanced renal cell carcinoma: overall survival analysis and updated results from a randomised phase 3 trial. Lancet Oncol. 2013;14(6):552-62.

31. Motzer RJ, Porta C, Vogelzang NJ, et al. Dovitinib versus sorafenib for third-line targeted treatment of patients with metastatic renal cell carcinoma: an open-label, randomised phase 3 trial. Lancet Oncol. 2014;15(3):286-96.

32. Hutson TE, Escudier B, Esteban E, et al. Randomized phase III trial of temsirolimus versus sorafenib as second-line therapy after sunitinib in patients with metastatic renal cell carcinoma. J Clin Oncol. 2014;32(8):760-7.

33. Motzer R, Rini B, McDermott D, et al. Nivolumab for metastatic renal cell carcinoma (mRCC): Results of a randomized, doseranging phase II trial. J Clin Oncol. 2014;32(15 suppl):abstr 5009. http://meetinglibrary.asco.org/content/125893-144. Accessed 1 July 2014.

34. Eggermont AM, Chiarion-Sileni V, Grob JJ, et al. Ipilimumab versus placebo after complete resection of stage III melanoma: 
initial efficacy and safety results from the EORTC 18071 phase III trial. J Clin Oncol. 2014;32(18 suppl):abstr LBA9008. http:// meetinglibrary.asco.org/content/130118-144. Accessed 1 July 2014.

35. Zitvogel L, Apetoh L, Ghiringhelli F, et al. Immunological aspects of cancer chemotherapy. Nat Rev Immunol. 2008;8(1): 59-73.

36. Calabrò L, Morra A, Fonsatti E, et al. A phase 2 single-arm study with tremelimumab at an optimized dosing schedule in secondline mesothelioma patients. J Clin Oncol. 2014;32(15 suppl):abstr 7531. http://meetinglibrary.asco.org/content/129923-144. Accessed 1 July 2014.

37. Fecher LA, Agarwala SS, Hodi FS, et al. Ipilimumab and its toxicities: a multidisciplinary approach. Oncologist. 2013;18(6): 733-43.

38. Topalian SL, Sznol M, McDermott DF, et al. Survival, durable tumor remission, and long-term safety in patients with advanced melanoma receiving nivolumab. J Clin Oncol. 2014;32(10): 1020-30.

39. Horn L, Herbst RS, Spigel D, et al. An analysis of the relationship of clinical activity to baseline EGFR status, PD-L1 expression and prior treatment history in patients with non-small cell lung cancer (NSCLC) following PD-L1 blockade with MPDL3280A (anti-PDL1). WCLC. 2013. Abstract MO18.01. https://www. webges.com/cview/library/wclc/home. Accessed 3 March 2014.

40. Calabrò L, Morra A, Fonsatti E, et al. Tremelimumab for patients with chemotherapy-resistant advanced malignant mesothelioma: an open-label, single-arm, phase 2 trial. Lancet Oncol. 2013;14(11):1104-11.

41. Beck KE, Blansfield JA, Tran KQ, et al. Enterocolitis in patients with cancer after antibody blockade of cytotoxic T-lymphocyteassociated antigen 4. J Clin Oncol. 2006;24(15):2283-9.

42. Weber JS, Kähler KC, Hauschild A. Management of immunerelated adverse events and kinetics of response with ipilimumab. J Clin Oncol. 2012;30(21):2691-7.

43. Attia P, Phan GQ, Maker AV, et al. Autoimmunity correlates with tumor regression in patients with metastatic melanoma treated with anti-cytotoxic T-lymphocyte antigen-4. J Clin Oncol. 2005;23(25):6043-53.

44. Zou W, Chen L. Inhibitory B7-family molecules in the tumour microenvironment. Nat Rev Immunol. 2008;8(6):467-77.

45. Hirano F, Kaneko K, Tamura H, et al. Blockade of B7-H1 and PD-1 by monoclonal antibodies potentiates cancer therapeutic immunity. Cancer Res. 2005;65(3):1089-96.

46. Wolchok JD, Hoos A, O'Day S, et al. Guidelines for the evaluation of immune therapy activity in solid tumors: immune-related response criteria. Clin Cancer Res. 2009;15(23):7412-20.

47. Seiwert TY, Burtness B, Weiss J, et al. A phase Ib study of MK3475 in patients with human papillomavirus (HPV)-associated and non-HPV-associated head and neck $(\mathrm{H} / \mathrm{N})$ cancer. J Clin Oncol. 2014;32(15 suppl):abstr 6011. http://meetinglibrary.asco. org/content/132361-144. Accessed 1 July 2014.

48. Antonia SJ, Brahmer JR, Gettinger S, et al. Nivolumab (anti-PD1; BMS-936558, ONO-4538) in combination with platinumbased doublet chemotherapy (PT-DC) in advanced non-small cell lung cancer (NSCLC). J Clin Oncol. 2014;32(15 suppl):abstr 8113. http://meetinglibrary.asco.org/content/125962-144. Accessed 1 July 2014.

49. Antonia SJ, Gettinger S, Chow LQ, et al. Nivolumab (anti-PD-1; BMS-936558, ONO-4538) and ipilimumab in first-line NSCLC: interim phase I results. J Clin Oncol. 2014;32(15 suppl):abstr 8023. http://meetinglibrary.asco.org/content/125736-144. Accessed 1 July 2014.

50. Rizvi NA, Chow LQ, Borghaei H, et al. Safety and response with nivolumab (anti-PD-1; BMS-936558, ONO-4538) plus erlotinib in patients (pts) with epidermal growth factor receptor mutant (EGFR MT) advanced NSCLC. J Clin Oncol. 2014;32(15 suppl):abstr 8022. http://meetinglibrary.asco.org/content/125751144. Accessed 1 July 2014

51. Berger R, Rotem-Yehudar R, Slama G, et al. Phase I safety and pharmacokinetic study of CT-011, a humanized antibody interacting with PD-1, in patients with advanced hematologic malignancies. Clin Cancer Res. 2008;14(10):3044-51.

52. Armand P, Welch S, Kim HT, et al. Prognostic factors for patients with diffuse large B cell lymphoma and transformed indolent lymphoma undergoing autologous stem cell transplantation in the positron emission tomography era. Br J Haematol. 2013;160(5):608-17.

53. Infante JR, Powderly JD, Burris HA, et al. Clinical and pharmacodynamic (PD) results of a phase I trial with AMP-224 (B7-DC Fc) that binds to the PD-1 receptor. J Clin Oncol. 2013;31(15 suppl):abstr 3044. http://meetinglibrary.asco.org/ content/117257-132. Accessed 17 April 2014.

54. Weber JS, Kudchadkar RR, Yu B, et al. Safety, efficacy, and biomarkers of nivolumab with vaccine in ipilimumab-refractory or -naive melanoma. J Clin Oncol. 2013;31(34):4311-8.

55. Hamid O, Robert C, Ribas A, et al. Randomized comparison of two doses of the anti-PD-1 monoclonal antibody MK-3475 for ipilimumab-refractory (IPI-R) and IPI-naive (IPI-N) melanoma (MEL). J Clin Oncol. 2014;32(15 suppl):abstr 3000. http:// meetinglibrary.asco.org/content/134788-144. Accessed 1 July 2014.

56. Kefford R, Ribas A, Hamid O, et al. Clinical efficacy and correlation with tumor PD-L1 expression in patients (pts) with melanoma (MEL) treated with the anti-PD-1 monoclonal antibody MK-3475. J Clin Oncol. 2014;32(15 suppl):abstr 3005. http://meetinglibrary. asco.org/content/130007-144. Accessed 1 July 2014.

57. Gandhi L, Balmanoukian A, Hui R, et al. MK-3475 (anti-PD-1 monoclonal antibody) for non-small cell lung cancer (NSCLC): antitumor activity and association with tumor PD-L1 expression. In: Presented at the American Association for Cancer Research (AACR) annual meeting 2014, 5-9 April 2014, San Diego. Abstract CT105. http://www.abstractsonline.com/Plan/View Abstract.aspx?sKey=1a1f4fbb-a45d-407f-861e-75f8d79db782 $\& \mathrm{cKey}=875 \mathrm{f} 683 \mathrm{f}-04 \mathrm{fe}-450 \mathrm{a}-\mathrm{a} 9 \mathrm{cb}-\mathrm{f} 51 \mathrm{cac} 5436 \mathrm{~b} 8 \& \mathrm{mKey}=6 \mathrm{ffe}$ 1446-a164-476a-92e7-c26446874d93. Accessed 17 April 2014.

58. Choueiri TK, Fishman MN, Escudier B et al. Immunomodulatory activity of nivolumab in previously treated and untreated metastatic renal cell carcinoma (mRCC): biomarker-based results from a randomized clinical trial. J Clin Oncol. 2014;32(15 suppl): abstr 5012. http://meetinglibrary.asco.org/content/125914-144. Accessed 1 July 2014.

59. Powderly JD, Koeppen H, Hodi FS, et al. Biomarkers and associations with the clinical activity of PD-L1 blockade in a MPDL3280A study. J Clin Oncol. 2013;31(15 suppl):abstr 3001. http://meetinglibrary.asco.org/content/112657-132. Accessed 1 July 2014.

60. Kisielow M, Kisielow J, Capoferri-Sollami G, et al. Expression of lymphocyte activation gene 3 (LAG-3) on B cells is induced by $\mathrm{T}$ cells. Eur J Immunol. 2005;35(7):2081-8.

61. Ngiow SF, Teng MW, Smyth MJ. Prospects for TIM3-targeted antitumor immunotherapy. Cancer Res. 2011;71(21):6567-71.

62. Zhu C, Anderson AC, Schubart A, et al. The Tim-3 ligand galectin-9 negatively regulates $\mathrm{T}$ helper type 1 immunity. Nat Immunol. 2005;6(12):1245-52.

63. Sabatos CA, Chakravarti S, Cha E, et al. Interaction of Tim-3 and Tim-3 ligand regulates $\mathrm{T}$ helper type 1 responses and induction of peripheral tolerance. Nat Immunol. 2003;4(11):1102-10.

64. Nocentini G, Ronchetti S, Petrillo MG, et al. Pharmacological modulation of GITRL/GITR system: therapeutic perspectives. $\mathrm{Br}$ J Pharmacol. 2012;165(7):2089-99.

65. Boczkowski D, Lee J, Pruitt $S$, et al. Dendritic cells engineered to secrete anti-GITR antibodies are effective adjuvants to dendritic 
cell-based immunotherapy. Cancer Gene Ther. 2009;16(12): 900-11.

66. Vella LJ, Pasam A, Dimopoulos N, et al. MEK inhibition, alone or in combination with BRAF inhibition, affects multiple functions of isolated normal human lymphocytes and dendritic cells. Cancer Immunol Res. 2014;2(4):351-60.

67. Amin A, Plimack ER, Infante JR, et al. Nivolumab (anti-PD-1; BMS-936558, ONO-4538) in combination with sunitinib or pazopanib in patients (pts) with metastatic renal cell carcinoma (mRCC). J Clin Oncol. 2014;32(15 suppl):abstr 5010. http:// meetinglibrary.asco.org/content/125881-144. Accessed 1 July 2014.
68. Hammers H, Plimack ER, Infante JR, et al. Phase I study of nivolumab in combination with ipilimumab in metastatic renal cell carcinoma (mRCC). J Clin Oncol. 2014;32(15 suppl):abstr 4504. http://meetinglibrary.asco.org/content/129458-144. Accessed 1 July 2014.

69. Westin JR, Chu F, Zhang M, et al. Safety and activity of PD1 blockade by pidilizumab in combination with rituximab in patients with relapsed follicular lymphoma: a single group, openlabel, phase 2 trial. Lancet Oncol. 2014;15(1):69-77. 